\title{
PROPOSTA DE MATRIZ PARA LEVANTAMENTO E AVALIAÇÃO DE IMPACTOS DE VIZINHANÇA
}

\section{A PROPOSED MATRIX TO NEIGHBORHOOD IMPACTS SURVEYING AND EVALUATION}

\author{
Lollo, J. A. ${ }^{1}$; Röhm, S. A. ${ }^{2}$ \\ ${ }^{1}$ Faculdade de Engenharia de Ilha Solteira - UNESP, Alameda Bahia, 550, 15385- \\ 000, Ilha Solteira - SP, e-mail: 1olloja@dec.feis.unesp.br \\ ${ }^{2}$ Centro De Ciências Exatas e de Tecnologia - UFSCar, Rodovia Washington Luís, \\ Km 235, 13565-905, São Carlos - SP, e-mail: sarohm@power.ufscar.br
}

\section{RESUMO}

O Estudo de Impacto de Vizinhança, instituído pela Lei 10.257/2001, é o instrumento legal disponível para a avaliação de impactos ambientais urbanos devidos à implantação de novos empreendimentos. Tal estudo engloba um grande número de intervenções no meio, de impactos possíveis, e de componentes ambientais afetados, o que torna bastante complexo sua execução. Em tal situação, a matriz de impactos é uma técnica muito útil, pois permite a identificação e a avaliação dos impactos de forma simples, ágil, e bastante flexível. A matriz proposta leva em conta cada uma das fases de implantação do empreendimento, os impactos esperados e os componentes ambientais afetados em cada caso. É também proposta uma classificação de impactos de vizinhança em quatro grupos: impactos no meio físico, impactos urbanísticos, impactos na infra-estrutura urbana, e em saneamento e qualidade de vida.

Palavras-chave: impacto de vizinhança, matriz de impactos, impactos ambientais, planejamento urbano, gestão ambiental.

\begin{abstract}
Neighborhood Impact Study, instituted by the Law $10.257 / 2001$, it is the available legal instrument for the evaluation of urban environmental impacts owed to the implantation of new enterprises. Such a study includes a large number of interventions in the environment, possible impacts, and affected environmental components, turning the work very complex. In this situation, impact matrix is a very useful technique, as it allows impacts identification and the evaluation in a simple, agile, and quite flexible way. The proposed matrix takes into account each phase of
\end{abstract}


enterprise implantation, the expected impacts and environmental components affected in each case. It is also proposed a classification of neighborhood impacts in four groups: impacts in the physical environment, town planning, urban infrastructure, and sanitation and quality of life.

Key words: neighborhood impacts, impacts matrix, environmental impacts, urban planning, environmental management.

\section{INTRODUÇÃO}

A avaliação de impactos no meio urbano devidos à instalação e operação de empreendimentos não contemplados na legislação federal que prevê a realização de Estudos de Impacto Ambiental foi, durante algum tempo, um problema de difícil solução, uma vez que não havia legislação que disciplinasse o tema.

A Lei 10.257/2001 estabeleceu os princípios gerais para tal tipo de análise ao propor um conjunto de fatores a serem avaliados quando da realização do Estudo Prévio de Impacto de Vizinhança, definido, pela mesma lei, como instrumento fundamental para "[...] obter as licenças ou autorizações de construção, ampliação ou funcionamento [...]" dos empreendimentos (BRASIL, 2001).

O uso do termo "impacto de vizinhança" para descrever impactos ocorridos em áreas urbanas, fruto de ações de empreendimentos urbanos, é registrado há mais de uma década, como se pode verificar em Moreira (1997), que descreve a existência de tal instrumento de gestão na Lei Orgânica do Município de São Paulo em 1990.

No decorrer da década de 90 outros municípios brasileiros, especialmente capitais, desenvolveram legislação própria que visava reduzir tais impactos.

Tais iniciativas concentravam sua atenção em ocupações de grande porte, como shopping centers e hipermercados e enfocavam especialmente impactos na paisagem urbana e nas vias de tráfego, como se pode verificar em Cymbalista (2001), Santoro e Nunes (2003) e Lollo (2004).

Alternativas de identificação de tais impactos também foram consideradas, bem como outros mecanismos de avaliação de impactos em meio urbano e indicadores da qualidade ambiental urbana.

Ribeiro e Falcoski (1998), discutem o conceito de desempenho ambiental e propõem seu uso como instrumento para avaliação de impactos em áreas urbanas. Brandão et. al. (2001), propõem o uso do coeficiente de aproveitamento para caracterizar o adensamento urbano e, desta forma, avaliar as necessidades urbanas fruto do crescimento.

Grigoletti e Sattler (2002), comparam oito métodos de avaliação de impactos da construção, ponderando vantagens e desvantagens de cada um. Crepaldi (2003), discute o conhecimento acerca dos impactos no meio urbano como base para a proposição de critérios e diretrizes para análise de propostas de ocupação do espaço urbano. 
Dias e Concenza (2004), propõem o uso de matrizes de impactos cruzados como mecanismo de análise de impactos no meio urbano.

Moreira (1992), propõe um roteiro básico para o Relatório de Impacto de Vizinhança que contempla: (1) caracterização do empreendimento, (2) caracterização da vizinhança, e (3) avaliação do impacto do empreendimento na vizinhança.

Para Santoro e Nunes (2003), avaliar tais impactos representa considerar, além dos benefícios que a implantação do empreendimento proporciona, os problemas futuros que ele pode trazer, de forma a intervir no processo.

Há que se considerar, ainda, a necessidade de atendimento à Lei 6.766, de 1979 que destaca que novas ocupações devem preservar a integridade e a qualidade dos serviços públicos como as redes de drenagem pluvial, iluminação pública, esgoto, abastecimento de água, e energia elétrica.

O objetivo básico da Lei 10.257 foi regulamentar os artigos 182 e 183 da Constituição Brasileira. Dentre os assuntos tratados tem-se o Estudo de Impacto de Vizinhança como instrumento de avaliação de propostas de ocupações e atividades urbanas (artigos 36 a 38).

O EIV veio cobrir uma lacuna na legislação brasileira no que diz respeito à avaliação de impactos ambientais decorrentes da ocupação urbana por empreendimentos não tratados pelas resoluções do Conselho Nacional de Meio Ambiente - CONAMA que definem a obrigatoriedade de realização de Estudos de Impacto Ambiental e produção de Relatórios de Impacto Ambiental (MATA, 2004).

A Lei preserva o princípio constitucional ao prever a competência da união em legislar quanto às normas gerais de direito urbanístico e política urbana, e remete à legislação municipal a definição da forma de aplicação dos princípios e instrumentos nela previstos.

A definição do município como responsável pela legislação ambiental urbana propicia as condições de que cada município trate suas questões ambientais de acordo com suas necessidades (GUIMARÃES, 2004).

Segundo a Lei 10.257/2001, o EIV deve incluir "a análise, no mínimo, das seguintes questões": adensamento populacional; equipamentos urbanos e comunitários; uso e ocupação do solo; valorização imobiliária; geração de tráfego e demanda por transporte público; ventilação e iluminação; paisagem urbana e patrimônio natural e cultural.

Apesar da existência de uma lei federal orientadora, e da experiência de vários municípios brasileiros em usar o EIV como instrumento de avaliação, algumas deficiências importantes podem ser notadas em tais estudos de impacto.

Tais deficiências podem ser divididas em duas categorias: deficiências provenientes da legislação e deficiências decorrentes da forma de condução dos trabalhos.

Um aspecto fundamental a se destacar na Lei 10.257 é que seu objetivo é normativo e genérico, para servir como orientação para a elaboração de leis municipais. No entanto, o que se observa na prática é que a maioria dos municípios 
que criam legislação para tratar do assunto, simplesmente repete os princípios existentes na Lei 10.257/2001.

Quando da proposição de leis municipais a expressão "no mínimo" costuma ser desconsiderada (por incapacidade ou conveniência), ficando as legislações municipais restritas aos tópicos propostos na lei federal.

Com relação à execução do estudo, as falhas podem ser resumidas em: falhas na caracterização do empreendimento e sua área de influência; falhas na definição espacial da vizinhança (a qual é variável segundo o componente presumivelmente impactado); e falhas no processo de avaliação dos impactos (desconsideração de aspectos importantes).

O empreendimento cujos impactos serão avaliados precisa ser muito bem caracterizado quanto a sua natureza, quanto ao ser porte, e quanto à proposta de ocupação, pois só assim sua área de influência será devidamente definida.

Quanto à vizinhança, é fundamental não só a caracterização de suas condições como a definição apropriada de suas dimensões. Tais dimensões devem ser adaptadas de acordo com o fator considerado.

As análises não podem se restringir ao sistema viário, a características urbanísticas e disponibilidade de infra-estrutura. Impactos sobre os recursos naturais, emissão de ruídos, emanação de gases e vapores e geração de resíduos devem ser levados em conta.

Considerando a diversidade de tipos de ocupações possíveis, de fatores potencialmente afetados no meio urbano, e a agilidade e pragmatismo necessários nesse tipo de estudo, a matriz de impactos ambientais (Matriz de Leopold) surge como o instrumento mais apropriado para levantamento e avaliação de tais impactos.

Assim, o presente trabalho tem por objetivo propor uma matriz de impactos para levantamento e avaliação de impactos de vizinhança, que contemple a diversidade de aspectos envolvidos num Estudo de Impacto de Vizinhança, do ponto de vista do tipo de empreendimento, dos componentes ambientais analisados, e da fase da ocupação considerada.

São considerados não só os componentes ambientais previstos na Lei 10.257/2001 como outros, de igual importância, não contemplados na lei. Os diferentes tipos de intervenção (construção, ampliação e ocupação de imóvel já existente) também são considerados.

A estrutura modular da tabela permite ainda que cada etapa (planejamento, construção/ampliação/ocupação, e operação) do empreendimento seja considerada isoladamente (caso seja necessário). De tal forma que se espera ter considerado todas as possibilidades envolvidas num estudo de impacto de vizinhança.

\section{PRESSUPOSTOS METODOLÓGICOS DA MATRIZ PROPOSTA}

A matriz de impactos foi escolhida, dentre as várias técnicas disponíveis de avaliação de impactos, no presente trabalho em função da agilidade, simplicidade e 
flexibilidade que permite ao levantamento e avaliação de impactos. Tal técnica foi originalmente proposta por Leopold et. al. (1971), sendo largamente usada quando se pretende fazer identificações e avaliações de impactos ambientai de forma ágil.

A proposta básica de uma matriz de impactos consiste em cruzar ações propostas com fatores ambientais, esses cruzamentos (que caracterizam os impactos ambientais) recebem notas que representam a magnitude dos impactos.

No presente trabalho tal estrutura básica foi mantida, mas com algumas alterações em função da peculiaridade dos impactos de vizinhança. Tais alterações dizem respeito à classificação dos impactos, à estrutura básica da matriz, às fases do empreendimento e intervenções correlatas, e aos componentes ambientais avaliados.

\subsection{Classificação dos Impactos}

Os impactos de vizinhança a serem avaliados na matriz foram classificados quanto à natureza, à ordem, à magnitude, e duração.

Quanto à natureza os impactos são classificados em positivos (impacto benéfico) e negativos (maléfico). Em termos da ordem, são divididos em diretos (tem sua causa claramente relacionada a ações do empreendimento) e indiretos (causa não exclusivamente relacionada a intervenções do empreendimento).

Com relação à magnitude, as classes propostas são: alta (alteração que descaracteriza o componente ambiental); baixa (alteração pouco significativa, pouco intensa, ou pouco complexa, no componente considerado), e média (descreve uma alteração de tal monta no componente ambiental afetado que compromete sua função, sem descaracterizá-lo).

No presente trabalho a designação média magnitude foi evitada ao máximo, dada sua subjetividade. Porém seu uso se faz necessário nas situações em que as magnitudes alta e baixa não sejam claramente caracterizadas.

Quanto à duração, os impactos foram classificados em permanente (quando não se configura prazo para término da intervenção ou previsão de tecnologia para controle ou recuperação do impacto) e temporário (condição em que há um prazo previsto para seu término, por execução dos trabalhos ou pela disponibilidade de tecnologia de controle).

$\mathrm{Na}$ presente proposta sugere-se evitar ao máximo a definição de impactos como temporários a não ser que se tenha certeza absoluta de tal situação (por exemplo, intervenções ocorridas apenas durante a construção do empreendimento). Em situações dúbias, nas quais "poderia haver solução dentro de algum tempo", o impacto deve ser considerado permanente.

\subsection{Estrutura da Matriz}

Com respeito à estrutura, a matriz proposta conserva a idéia original de Leopold et. al. (1971), porém algumas adaptações foram feitas, de forma a adequar a matriz à realidade do trabalho proposto. 
Assim, a estrutura contempla as categorias de informação (aspectos da ocupação, suas conseqüências, componentes ambientais avaliados, medidas mitigadoras e compensatórias previstas) em colunas, enquanto as ações propriamente ditas são descritas e têm seus impactos avaliados em linhas da matriz. As fases do empreendimento consideradas para fim de avaliação de impacto de vizinhança são: Planejamento; Construção/Adaptação/Ocupação; Operação. A figura 1 ilustra a estrutura descrita.

A estrutura modular da matriz trás duas vantagens evidentes. A primeira delas é que permite que os impactos sejam avaliados a cada fase, possibilitando a discussão da importância que cada fase representa na qualidade ambiental da vizinhança, e proporcionando alternativas para distinção entre empreendimentos que representem construção, daqueles decorrentes de adaptações ou ampliações em edificações já existentes.

Tal situação permite tratar igualmente as duas realidades descritas (construção $\mathrm{x}$ adaptação/ampliação), sem que os impactos gerados pelo segundo grupo sejam menosprezados. No caso de adaptação/ampliação, tal proposta permite ainda que sejam valorizadas apenas intervenções coerentes com o processo.

\begin{tabular}{|c|c|c|c|c|c|c|c|}
\hline \multirow{2}{*}{$\begin{array}{l}\text { Fase do } \\
\text { Empreendimento } \\
\text { Planejamento }\end{array}$} & \multirow{2}{*}{$\begin{array}{l}\text { Intervenção } \\
\text { Prevista } \\
\text { descrição }\end{array}$} & \multirow{2}{*}{\begin{tabular}{|l|} 
Impacto \\
Previsto \\
descrição
\end{tabular}} & \multicolumn{4}{|c|}{$\begin{array}{l}\text { Componentes } \\
\text { Avaliados }\end{array}$} & \multirow{2}{*}{$\begin{array}{l}\text { Medidas } \\
\text { Propostas } \\
\text { descrição }\end{array}$} \\
\hline & & & $\mathrm{I}+$ & $\mathrm{A}+$ & M- & $\mathrm{D}+$ & \\
\hline & & descrição & $\mathrm{T}+$ & D- & $\mathrm{B}+$ & $\mathrm{P}+$ & descrição \\
\hline & descrição & descrição & $\mathrm{M}+$ & $\mathrm{P}-$ & T- & I- & descrição \\
\hline & & descrição & A- & $\mathrm{T}+$ & I+ & M- & descrição \\
\hline & descrição & descrição & $\mathrm{P}+$ & $\mathrm{I}+$ & $\mathrm{B}+$ & D+ & descrição \\
\hline & & descrição & $\mathrm{A}+$ & $\mathrm{M}+$ & $\mathrm{T}+$ & $\mathrm{P}-$ & descrição \\
\hline & & descrição & D- & $\mathrm{T}-$ & $\mathrm{A}+$ & I- & descrição \\
\hline & descrição & descrição & B- & $\mathrm{D}+$ & $\mathrm{P}+$ & A- & descrição \\
\hline Construção & descrição & descrição & $\mathrm{I}+$ & $\mathrm{P}-$ & $\mathrm{D}+$ & B- & descrição \\
\hline Adaptação & descrição & descrição & P- & $\mathrm{A}+$ & I- & $\mathrm{T}+$ & descrição \\
\hline & descrição & descrição & $\mathrm{P}-$ & $\mathrm{B}+$ & $\mathrm{M}+$ & D- & descrição \\
\hline & descrição & descrição & M- & I- & T- & A- & descrição \\
\hline Operação & descrição & descrição & $\mathrm{D}+$ & $\mathrm{A}+$ & P- & M- & descrição \\
\hline & descrição & descrição & A- & B- & T- & I- & descrição \\
\hline & descrição & descrição & $\mathrm{T}-$ & $\mathrm{I}+$ & $\mathrm{A}+$ & $\mathrm{B}+$ & descrição \\
\hline & descrição & descrição & $\mathrm{M}+$ & $\mathrm{P}+$ & B- & D- & descrição \\
\hline
\end{tabular}

Figura 1- Representação esquemática da estrutura da matriz de impactos proposta. 


\subsection{Componentes Ambientais Avaliados}

Como já discutido, a legislação vigente possui falhas no que diz respeito à definição dos componentes ambientais a serem avaliados em EIV. Sendo assim, o presente trabalho procurou detalhar ao máximo os componentes passíveis de impactos em cada uma das fases do empreendimento em análise.

Com o objetivo de estruturar melhor a identificação dos impactos, estes foram agrupados em quatro categorias: meio físico; aspectos urbanísticos; infra-estrutura urbana; e saneamento e qualidade de vida.

No primeiro grupo (meio físico) os componentes considerados são: ar, solos, rochas, relevo, mananciais superficiais, mananciais subterrâneos, paisagem natural, vegetação, uso e ocupação do solo.

Os componentes da categoria "aspectos urbanísticos" tratam de atributos que podem vir a sofrer impactos por ações ou intervenções do empreendimento. Tais componentes são: densidade populacional, densidade urbana, mercado imobiliário, ventilação, iluminação, paisagem urbana, patrimônio cultural, qualidade urbanística.

Apesar de não apresentarem a característica fundamental dos componentes ambientais normalmente usados em estudos de impacto ambiental, que é o pragmatismo na caracterização do componente, que permite a mensuração das alterações sofridas, tais componentes são fundamentais para caracterizar as alterações urbanísticas sofridas pela vizinhança, decorrentes da implantação de um empreendimento.

No grupo "infra-estrutura urbana" encontra-se os componentes de serviços e matérias-primas usados pelo empreendimento: vias urbanas, transporte coletivo urbano, redes de água, esgoto, drenagem pluvial, energia elétrica, telefonia, iluminação pública, e segurança pública.

Neste, mais que qualquer outro grupo, o poder público tem alternativas de impor medidas compensatórias para a sociedade como um todo, dado o fato que tais serviços são imprescindíveis para qualquer empreendimento.

$\mathrm{Na}$ categoria de componentes denominada "Saneamento e Qualidade de Vida" se encontram os componentes: ruídos, resíduos sólidos urbanos, resíduos líquidos urbanos, e resíduos industriais.

\section{IMPACTOS DE VIZINHANÇA PREVISTOS NA PROPOSTA}

Antes da apresentação dos impactos de vizinhança que se pode prever num EIV e que compõem a matriz de impactos proposta, é importante caracterizar os componentes ambientais considerados e sua importância na identificação de impactos.

\subsection{Componentes do Meio Físico}

Para os componentes do solo devem ser identificados processos de degradação física (como erosão) e degradação química (contaminação e poluição). Para as rochas 
é seguido o mesmo raciocínio. Alterações no relevo podem prejudicar a qualidade visual e criar impactos na circulação das águas e resultar em degradação física e química de águas, solo e rocha.

Mananciais superficiais presentes na vizinhança podem ser afetados por assoreamento, lançamento de redes de drenagem e esgoto, uso como bota-fora, recepção ou contato com resíduos gerados pelo empreendimento.

No caso dos mananciais subterrâneos, os levantamentos dizem respeito às possibilidades de contaminação e poluição decorrentes de atividades do empreendimento. O mesmo se pode dizer com relação ao ar.

Com respeito à paisagem natural, é necessário identificar processos relativos à implantação da empresa que tenham destruído, degradado ou descaracterizado a paisagem natural (composição de variáveis do meio físico que tem uma expressão na paisagem).

Para a vegetação deve ser considerada a degradação ou eliminação de espécies vegetais que o empreendimento possa causar. A caracterização do uso e ocupação do solo tem por objetivo verificar a compatibilidade do empreendimento com as ocupações vizinhas e o potencial que o empreendimento apresenta em induzir alterações no uso e ocupação na vizinhança.

\subsection{Aspectos Urbanísticos}

No caso da densidade populacional, se devem identificar variações na vizinhança que possam ser direta (aumento populacional devido à chegada de pessoas que trabalharão no empreendimento) ou indiretamente (mudança de pessoas para a vizinhança em virtude de benefícios advindos do empreendimento ou de empregos indiretos por ele gerados) relacionados ao empreendimento. Raciocínio similar se aplica à densidade urbana.

As variações no mercado imobiliário dizem respeito a valorizações ou desvalorizações imobiliárias ocorridas na vizinhança em virtude da existência do empreendimento. Com relação à iluminação e ventilação, importa caracterizar como o empreendimento influencia esses atributos para as edificações presentes na vizinhança.

Identificar alterações na Paisagem Urbana implica levantar danos ou obstruções causados pelo empreendimento à estética urbana, bem como alterações nas destinações das edificações vizinhas, fruto da implantação do empreendimento, enquanto o título Qualidade Urbanística engloba transformações urbanísticas tais como alterações no traçado urbano e no padrão construtivo da vizinhança, relacionadas, de alguma forma, ao empreendimento.

"Patrimônio Cultural" representa não só prédios que possam integrar o patrimônio histórico, mas fachadas, pinturas, jardins, e outros componentes da estética urbana que se pretenda preservar que possam ser afetados pelo empreendimento. 


\subsection{Infra-estrutura Urbana}

Com relação às vias urbanas, deve ser identificada a geração de tráfego relacionada ao empreendimento e a demanda por estacionamento que este representa. Com relação ao transporte urbano coletivo interessa identificar a demanda por transporte urbano gerada pelo empreendimento.

Para as redes de utilidade (água, esgoto, elétrica, telefonia, iluminação pública e drenagem pluvial) cabe identificar as necessidades do empreendimento, sua demanda por tais serviços e alternativas de satisfação de tal demanda e seu impacto na vizinhança.

No tocante à segurança pública, se deve identificar se o empreendimento é fator aumento da criminalidade na área, identificando as condições atuais de segurança pública e a relação de tal problema com a instalação da empresa.

\subsection{Saneamento e Qualidade de Vida}

Quanto à ocorrência de emissão de ruídos, deve ser verificada e geração de ruídos esperada para o empreendimento e sua compatibilidade coma a vizinhança. Quanto aos resíduos (sólidos e líquidos urbanos, e industriais) cabe identificar geração e destinação no empreendimento e os impactos que eles podem gerar na vizinhança.

\subsection{Matriz de Impactos x Fase do Empreendimento}

Como o número de componentes ambientais a serem avaliados, o número de impactos possíveis e a complexidade das relações entre intervenções e componentes é bastante grande, a apresentação da matriz completa, numa forma inteligível fica muito difícil.

Por essa razão, no presente trabalho se fez a opção de apresentar parcelas da matriz de impacto na forma sintética, ou seja, a matriz será apresentada em três parcelas, coerentes com as seguintes fases do empreendimento: (1) Planejamento; (2) Construção/Adaptação/ Ocupação (conforme o caso); e (3) Operação.

Como existem três possibilidades distintas quanto à instalação física do empreendimento (construção do prédio onde será instalado; adaptação de prédio já existente; e simples ocupação da edificação), cada possibilidade representando diferentes potenciais de geração de impactos, é proposto um sistema de cores para representar os impactos.

Assim, a cor vermelha foi usada para a situação na qual o impacto pode se dar nas três fases do empreendimento (construção, adaptação ou ocupação), a cor azul quando só há possibilidade do impacto ocorrer em caso de adaptação e construção, e a cor verde quando o impacto só é possível quando se tratar de construção.

Para cada fase de empreendimento as parcelas da tabela contêm as intervenções previstas, os impactos de vizinhança esperados, e os componentes ambientais afetados e a classificação quanto à natureza (D-direto, ou I-indireto). Para 
ilustrar as relações entre intervenções, impactos e componentes, tais parcelas são apresentadas na forma de tabelas.

$\mathrm{Na}$ Tabela 1 são apresentadas as informações relativas à fase de Planejamento, na Tabela 2, a fase de Construção/Adaptação/ Ocupação, e na Tabela 3, a fase de Operação.

\section{CONCLUSÕES}

O Estudo de Impacto de Vizinhança pode ser um instrumento interessante para avaliação de impactos decorrentes da implantação de novos empreendimentos urbanos, desde que os componentes ambientais tratados não se limitem àqueles previstos na Lei 10.257.

A matriz de impactos pode ser uma ferramenta bastante apropriada para avaliação de impactos de vizinhança desde que cada atributo seja avaliado levando-se em conta a fase de implantação do empreendimento e todos os componentes ambientais direta ou indiretamente afetados.

\section{AGRADECIMENTOS}

Os autores agradecem o Conselho Nacional de Desenvolvimento Científico e Tecnológico - CNPq pelo apoio ao desenvolvimento do projeto, por meio do processo 150181/2004-3. 
Tabela 1. Intervenções previstas, impactos esperados e componentes ambientais afetados na Fase de Planejamento.

\begin{tabular}{|c|c|c|}
\hline Intervenção & Impactos Esperados & $\begin{array}{l}\text { Componentes Ambientais } \\
\text { Afetados }\end{array}$ \\
\hline \multirow{2}{*}{$\begin{array}{lr}\text { Seleção } & \text { de } \\
\text { Locais } & \mathrm{e} \\
\text { Alternativas } & \\
\text { Técnicas } & \end{array}$} & Especulação imobiliária & $\begin{array}{llr}\text { Mercado } & \text { Imobiliário } & \text { (D), } \\
\text { Patrimônio } & \text { Cultural } & \text { (I), } \\
\text { Paisagem } & \text { Natural } & \text { (I), } \\
\text { Vegetação } & \text { (I), Uso } & \text { e } \\
\text { Ocupação (I). } & & \\
\end{array}$ \\
\hline & Compra ou desapropriação & 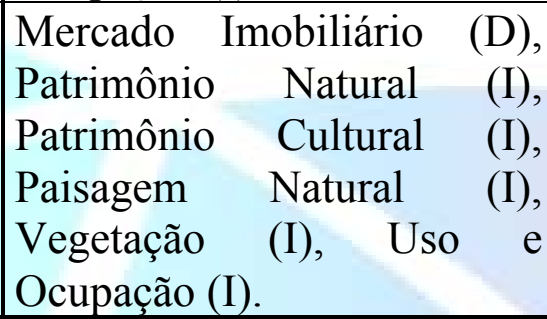 \\
\hline \multirow{3}{*}{$\begin{array}{l}\text { Levantamentos } \\
\text { de campo }\end{array}$} & Movimentação de veículos & $\begin{array}{l}\text { Vias Urbanas } \\
\text { Patrimônio Cultural } \\
\text { (I), Ar } \\
\text { (D), Nível de Ruído (D). }\end{array}$ \\
\hline & Operação de máquinas & 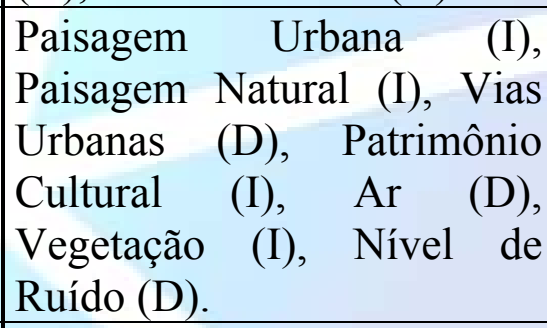 \\
\hline & Operação de equipamentos & $\begin{array}{l}\text { Paisagem Urbana } \\
\text { Patrimônio Cultural (I), Ar } \\
\text { (D), Nível de Ruído (D). }\end{array}$ \\
\hline $\begin{array}{l}\text { Desapropriação } \\
\text { ou aquisição }\end{array}$ & Especulação imobiliária & 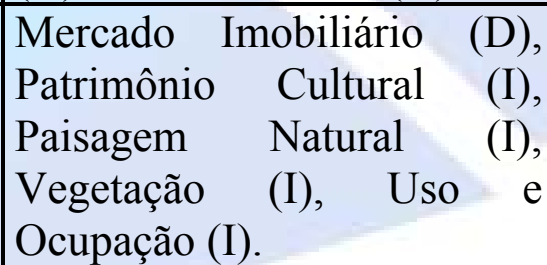 \\
\hline
\end{tabular}


Tabela 2. Intervenções previstas, impactos esperados e componentes ambientais afetados na Fase de Construção.

\begin{tabular}{|c|c|c|}
\hline Intervenção & Impactos Esperados & Componentes Ambientais Afetados \\
\hline $\begin{array}{l}\text { Criação } \\
\text { acessos }\end{array}$ & $\begin{array}{l}\text { Descaracterização } \\
\text { faixa de domínio }\end{array}$ & $\begin{array}{l}\text { Patrimônio Cultural (I), Qualidade urbanística } \\
\text { (I), Vias urbanas (D), Transporte Urbano (D), } \\
\text { Solos (D), Rochas (I), Relevo (D), Manancial } \\
\text { de superfície (I), Manancial subterrâneo (I), } \\
\text { Paisagem natural (I), Vegetação (I), Uso e } \\
\text { Ocupação (I), Nível de ruído (I). }\end{array}$ \\
\hline $\begin{array}{l}\text { Adaptação de } \\
\text { acessos }\end{array}$ & $\begin{array}{l}\text { Descaracterização } \\
\text { faixa de domínio }\end{array}$ & $\begin{array}{l}\text { Patrimônio Cultural (I), Qualidade urbanística } \\
\text { (I), Vias urbanas (I), Transporte Urbano (D), } \\
\text { Uso e Ocupação (I), Nível de ruído (I). }\end{array}$ \\
\hline \multirow{3}{*}{ Terraplanagem } & $\begin{array}{l}\text { Movimentação } \\
\text { veículos }\end{array}$ & $\begin{array}{l}\text { Vias Urbanas (D), Patrimônio Cultural (I), Ar } \\
\text { (D), Nível de Ruído (D). }\end{array}$ \\
\hline & Operação de máquinas & $\begin{array}{l}\text { Paisagem Urbana (I), Paisagem Natural (I), } \\
\text { Vias Urbanas (D), Patrimônio Cultural (I), Ar } \\
\text { (D), Vegetação (I), Nível de Ruído (D). }\end{array}$ \\
\hline & $\begin{array}{l}\text { Operação } \\
\text { equipamentos }\end{array}$ & $\begin{array}{l}\text { Paisagem Urbana (I), Patrimônio Cultural (I), } \\
\operatorname{Ar} \text { (D), Nível de Ruído (D). }\end{array}$ \\
\hline \multirow{2}{*}{$\begin{array}{ll}\text { Instalação } & \text { do } \\
\text { canteiro } & \text { de } \\
\text { obras } & \end{array}$} & $\begin{array}{l}\begin{array}{l}\text { Ligações à infra-estrutura } \\
\text { urbana }\end{array} \\
\end{array}$ & $\begin{array}{l}\text { Rede de água (D), Rede de esgoto (D), Rede de } \\
\text { drenagem pluvial (D), Rede elétrica (D), Rede } \\
\text { telefônica (I), Rede de iluminação pública (I), } \\
\text { Solos (I), Rochas (I), Manancial superficial (I), } \\
\text { Manancial subterrâneo (I), Nível de ruído (D). }\end{array}$ \\
\hline & $\begin{array}{|lr|}\text { Transporte } & \mathrm{e} \\
\text { armazenamento } & \mathrm{de} \\
\text { materiais de construção } & \end{array}$ & 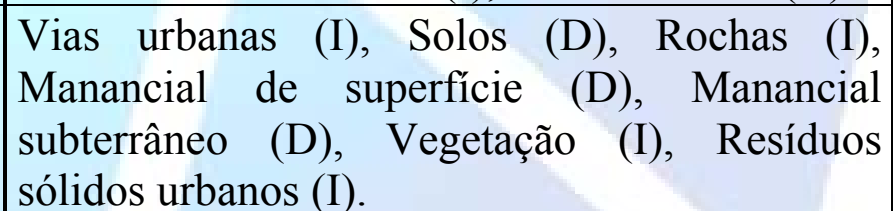 \\
\hline $\begin{array}{l}\text { Obras de } \\
\text { construção, } \\
\text { drenagem e e } \\
\text { pavimentação. }\end{array}$ & $\begin{array}{l}\text { Escavações, geração de } \\
\text { resíduos de construção. }\end{array}$ & $\begin{array}{l}\text { Vias urbanas (D), Rede de água (I), Rede de } \\
\text { esgoto (I), Rede de drenagem pluvial (I), Solos } \\
\text { (D), Rochas (D), Manancial superficial (I), } \\
\text { Manancial subterrâneos (I), Resíduos sólidos } \\
\text { urbanos (D). }\end{array}$ \\
\hline
\end{tabular}


Tabela 3. Intervenções previstas, impactos esperados e componentes ambientais afetados na Fase de Operação.

\begin{tabular}{|c|c|c|}
\hline Interv & os Esperados & Componentes Ambientais Afetados \\
\hline Instalação & $\begin{array}{l}\text { Alteração do uso da } \\
\text { edificação }\end{array}$ & $\begin{array}{l}\text { Densidade populacional (I), Densidade urbana } \\
\text { (I), Patrimônio Cultural (I), Mercado imobiliário } \\
\text { (D), Ventilação (D), Iluminação (D), Paisagem } \\
\text { urbana (D), Patrimônio cultural (I), Qualidade } \\
\text { urbanística (I), Vias Urbanas (I), Transporte } \\
\text { Urbano (I), Rede de água (I), Rede de esgoto (I), } \\
\text { Rede elétrica (I), Rede telefônica (I), Iluminação } \\
\text { pública (I), Segurança públicos (I), Resíduos } \\
\text { sólidos urbanos (D). }\end{array}$ \\
\hline \multirow{2}{*}{$\begin{array}{lr}\text { Demanda } & \text { por } \\
\text { insumos } & \mathrm{e} \\
\text { infra-estrutura }\end{array}$} & de & \\
\hline & Gerência de materiais & $\begin{array}{l}\text { o (I), Rede elétrica (I), Rede } \\
\text { uminação pública (I), Segurança } \\
\text { ssformações urbanísticas (I). }\end{array}$ \\
\hline \begin{tabular}{ll|l} 
Entrada & de \\
matérias- & & \\
primas & & 1
\end{tabular} & $\begin{array}{l}\text { Circulação } \\
\text { materiais }\end{array}$ & $\begin{array}{l}\text { Ar (D), Paisagem natural (I), Vias urbanas (I), } \\
\text { Segurança pública (I), Transformações } \\
\text { urbanísticas (I), Ruído (D). }\end{array}$ \\
\hline $\begin{array}{l}\text { Saída } \\
\text { produtos }\end{array}$ & $\begin{array}{l}\text { Circulação } \\
\text { materiais }\end{array}$ & $\begin{array}{l}\text { Ar (D), Paisagem natural (I), Vegetação (I), Uso } \\
\text { e ocupação (I), Vias urbanas (I), Segurança } \\
\text { pública (I), Transformações urbanísticas (I), } \\
\text { Ruído (D), Resíduos sólidos (D), Resíduos } \\
\text { líquidos(D) e Resíduos Industriais (D). }\end{array}$ \\
\hline $\begin{array}{l}\text { Circulação de } \\
\text { pessoal }\end{array}$ & 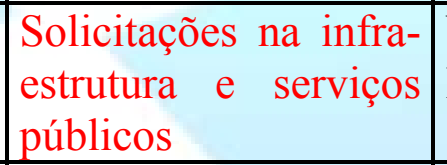 & $\begin{array}{l}\text { Vias urbanas (D), Transporte urbano (D), } \\
\text { Iluminação pública (D), Segurança pública (D). }\end{array}$ \\
\hline $\begin{array}{ll}\text { Sistemas } & \text { de } \\
\text { produção } & \\
\text { industrial } & \end{array}$ & \begin{tabular}{|l|l|}
$\begin{array}{l}\text { Solicitações } \\
\text { estrutura infra- }\end{array}$ \\
públicos
\end{tabular} & $\begin{array}{l}\text { Solos (D), Rocha (D), Mananciais superficiais } \\
\text { (D), Mananciais subterrâneos (D), Ar (D), } \\
\text { Vegetação (I), Uso e ocupação (I), Rede de água } \\
\text { (D), Rede elétrica (D), Paisagem urbana (I), } \\
\text { Ruído (D), Resíduos sólidos (D), Resíduos } \\
\text { líquidos (D) e Resíduos Industriais (D). }\end{array}$ \\
\hline \begin{tabular}{l|l} 
Atendimento, \\
vendas \\
escritórios.
\end{tabular} & \begin{tabular}{|lr|}
\multicolumn{3}{|c|}{ Solicitações } & na infra- \\
estrutura, & serviços \\
públicos e & materiais \\
da empresa. & \\
\end{tabular} & $\begin{array}{l}\text { Mananciais superficiais (D), Mananciais } \\
\text { subterrâneos (D), Ar (D), Vias Urbanas (I), Rede } \\
\text { de esgoto (I), Rede elétrica (I), Rede telefônica } \\
\text { (I), Iluminação pública (I), Segurança pública } \\
\text { (I), Ruído (D), Resíduos sólidos (D), Resíduos } \\
\text { líquidos(D). }\end{array}$ \\
\hline
\end{tabular}




\section{REFERÊNCIAS}

BRANDÃO, R. S., TEIXEIRA, R.P.V.B., MENDONÇA, R.S.R., PAIVA, J.E.M.; ASSIS, E.S. Ferramenta para previsão de impactos ambientais: prognósticos para um bairro de Belo Horizonte, MG. In: ENCONTRO LATINO-AMERICANO SOBRE CONFORTO NO AMBIENTE CONSTRUÍDO, 3., 2001, São Pedro. ANAIS... São Pedro: ANTAC, 2001. p. 1-8.

BRASIL. Lei 10.257, de 10 de Julho de 2001. Regulamenta os arts. 182 e 183 da Constituição Federal, estabelece as diretrizes gerais da política urbana e dá outras providências. Diário Oficial da União, Brasília, 11 de jul. 2001.

CREPALDI, P. V. Projeto urbano sustentável como referencial teórico-conceitual para critérios e diretrizes para análise de projetos e empreendimentos de impacto urbanístico. In: ENCONTRO NACIONAL SOBRE EDIFICAÇÕES E CIDADES SUSTENTÁVEIS, 3., 2003, ANAIS... São Paulo: III ENECS, 2003, 1 CD-Rom.

CYMBALISTA, R. Estudo de impacto de vizinhança. Disponível em: $<$ http://www.polis.org.br/publicacoes/dicas/default.asp>. Acesso em: 29 jun. 2004.

DIAS, M. A.; COCENZA, O. N. Matrizes de impactos cruzados - um instrumento de orientação dos efeitos da intervenções no meio ambiente. Disponível em: $<$ http://www.habitare.com.br/>. Acesso em: 20 ago. 2004.

GRIGOLETTI, G. C.; SATTLER, M. A. Impactos ambientais associados a materiais de construção - análise de ferramentas existentes. In: NUTAU 2002, 2002, São Paulo. ANAIS... São Paulo: NUTAU/USP, 2002. p. 1409-1420.

GUIMARÃES, J. P. Competência Constitucional dos Municípios em Matéria Ambiental. In: COUTINHO, R.; ROCCO, R. (Org.) O Direito Ambiental das Cidades. Rio de Janeiro: DP\&A, 2004. p. 85-102.

LEOPOLD, L. B.; CLARKE, F. E.; HANSHAW, B. B.; BAISLEY, J. R. A procedure for Evaluating Environmental Impact. Washington: USGS, 1971, 13p. (Circular 645).

LOLLO, J. A. Utilização de sistema de informações geográficas em estudo de impacto de vizinhança: o caso do pólo tecnológico de São Carlos. São Carlos: UFSCar, 2004. 62 p. (Relatório encaminhado ao CNPq). 
MATA, L. R. O Estatuto da Cidade à Luz do Direito Ambiental. In: COUTINHO, R.; ROCCO, R. (organizadores) O Direito Ambiental das Cidades. Rio de Janeiro: DP\&A, 2004. p. 103-142.

MOREIRA, A. C. .M. L. Mega-projetos \& Ambiente Urbano: uma metodologia para elaboração de relatório de impacto de vizinhança. 1997. 66p. Tese (Doutorado em Arquitetura e Urbanismo) - Faculdade de Arquitetura e Urbanismo, Universidade de São Paulo, São Paulo, 1997.

MOREIRA, A. C. .M. L. Relatório de impacto de vizinhança. Sinopses, São Paulo, n. 18, p. 23-25, FAUUSP, dezembro, 1992.

RIBEIRO, E. R.; FALCOSKI, L. A. N. Desempenho ambiental: delimitação conceitual como subsídio à elaboração de instrumentos para avaliação de impactos ambientais em áreas urbanas. Disponível em: $<\mathrm{http}: / / \mathrm{www}$.habitare.com.br/>. Acesso em: 14 ago. 2004.

SANTORO, P.; NUNES, J. Avaliar o impacto de grandes empreendimentos. Disponível em: <http://www.polis.org.br/publicacoes/dicas/default.asp >. Acesso em: 29 jun. 2004. 